\title{
PLANEJAMENTO, ELABORAÇÃO E UTILIZAÇÃO DE MATERIAIS DIDÁTICOS DISPONIBILIZADOS EM AMBIENTE VIRTUAL DE APRENDIZAGEM
}

\author{
SÃO BERNARDO DO CAMPO/SP JUNHO/2018
}

\author{
Regiane Maria Tomé Faim \\ - UMESP - regiane.faim@gmail.com \\ Adriana Barroso de Azevedo \\ - UMESP - adriana.azevedo@metodista.br \\ Tipo: Investigação Científica (IC) \\ Natureza: Relatório Final de Pesquisa \\ Categoria: Métodos e Tecnologias \\ Setor Educacional: EDUCAÇÃO SUPERIOR
}

\begin{abstract}
RESUMO
A organização de um curso na modalidade a distância exige conhecimentos e comprometimento no exercício da profissão docente, como a construção de saberes específicos para a elaboração de aulas e o gerenciamento do ambiente virtual de aprendizagem (AVA). Neste sentido, ao darmos voz aos alunos de um curso de educação a distância (EaD), por meio de suas experiências e percepções descritas em suas vivências com o ambiente virtual de aprendizagem (AVA), presumimos que isto poderá contribuir para aprimorar a prática docente na modalidade a distância, estimulando a busca de novas metodologias para a melhoria no processo de ensino-aprendizagem. Portanto, neste artigo, refletimos sobre as experiências dos alunos na utilização do AVA, por meio de suas narrativas, considerando os recursos e atividades nele disponíveis e as contribuições do AVA para o ensinoaprendizagem e para a formação docente. Abordamos primeiramente aspectos da educação a distância, da docência no século XXI e da autoria docente. Em seguida, analisamos as teorias e concepções do ambiente virtual de aprendizagem, do planejamento pedagógico para a educação a distância e da produção do material didático. Ao fim, partimos da análise hermenêutico-fenomenológica (AHF) com a interpretação dos registros textuais das experiências vivenciadas pelos participantes no AVA, e chegamos à essência do fenômeno por meio dos processos de textualização e tematização (operacionalizada pelas rotinas de organização e interpretação). Do ciclo de validação emergiram quatro grandes temas: busca, fluência, vias e mediação, cujos desdobramentos viabilizaram reflexões sobre a formação na modalidade a distância, o planejamento do conteúdo, o uso do recursos e atividades no AVA e a interação entre professores e alunos, que, que podem e devem continuar a ser o objetivo maior dos profissionais que atuam ou venham a atuar na modalidade a distância.
\end{abstract}

Palavras-chave: Formação de Professores. Educação a Distância. Planejamento. Material Didático. 


\section{Educação a distância e a docência no século XXI: desafios contemporâneos}

Dentre os diversos desafios presentes na Educação a Distância está a formação dos profissionais que atuam nesta área, desde professores/autores/tutores até equipes responsáveis pelas diferentes fases de produção. Esses profissionais, além de trabalharem em sintonia para o planejamento e a elaboração dos materiais didáticos, precisam ter o conhecimento e a sensibilidade no momento da escolha dos recursos e das atividades que serão disponibilizados no ambiente virtual de aprendizagem. Portanto, quando se concebe a prática docente não se pode deixar de considerar a autoria e os caminhos reflexivos percorridos para produção dos materiais didáticos. Ricardo (2013) pontua a dificuldade na capacitação de professores autores para a EaD, pois esta não ocorre na formação inicial nem continuada nas universidades; o que se verifica é uma formação aligeirada, focada nas necessidades específicas de cada instituição.

\section{Ambiente virtual de aprendizagem: algumas considerações}

O conceito de ambiente virtual de aprendizagem (AVA), também denominado Learning Management Systems (LMS) ou sistemas de gerenciamento do aprendizado, compreende softwares, disponibilizados na internet, que reúnem ferramentas para a criação, a tutoria e a gestão de atividades, que geralmente se apresentam na forma de cursos. Convém esclarecermos que "[...] quanto mais bem organizado o site do curso, mais fácil será a utilização da tecnologia por parte dos alunos. Se não encontrarem dificuldades com o uso da tecnologia, os alunos terão uma participação mais ativa no curso" (PALLOFF; PRATT, 2002, p. 133), mas, para que isso ocorra efetivamente durante o período do curso, as instituições de ensino precisam garantir o funcionamento das tecnologias e fornecer suportes midiáticos para solução de problemas que poderão ocorrer. Partindo daí, podemos perceber que o maior desafio dos professores está em apresentar ou propor atividades autorais e compartilhadas que promovam a interação com os alunos. "Por mais experiente que seja o especialista em conteúdo, criar um recurso didático, seja ele um livro impresso ou um objeto de aprendizagem, não é a mesma coisa que dar uma aula, proferir uma palestra ou ministrar um curso" (FILATRO; CAIRO, 2015, p. 280).

\section{Metodologia e procedimentos de interpretação}

Pautamos, metodologicamente, na pesquisa narrativa, à luz de Clandinin e Connelly (2015, p. 51), que a conceituam como "[...] uma forma de compreender a experiência. É um tipo de colaboração entre pesquisador e participantes, ao longo do mesmo tempo, em um lugar ou série de lugares, e em interação com milieus". Nessa lógica, ao contar sua própria história por meio de sua narrativa, "[...] a pessoa procura dar sentido às suas experiências e, nesse percurso, constrói outra representação de si: reinventa-se" 
(PASSEGGI, 2011, p. 147), oportunizando, assim, que esses futuros professores narrem suas experiências e reflitam suas práticas. As narrativas reveladas no ambiente virtual de aprendizagem foram interpretadas pela abordagem hermenêutico-fenomenológica (AHF), na forma como inspirou-se Maximina Freire $(2012,2015)$ ao ser "[...] atraída pela proposta metodológica de van Manen (1990), ao sugerir a união de fenomenologia e hermenêutica" (FREIRE M., 2015, p. 173). A autora considera que "[...] a interpretação apresentada foi aquela que Ihe foi possível, naquele momento sócio-histórico-pessoal, considerando o seu referencial teórico e experiencial” (FREIRE M., 2012, p. 196).

A pesquisa foi realizada em um curso de Pedagogia, na modalidade a distância, de uma universidade da cidade de São Bernardo do Campo, mais especificamente com os alunos do $4^{\circ}$ período. Semanalmente, o aluno assiste a uma teleaula ministrada por um professor temático, com a duração de 1 hora e 40 minutos, transmitida via satélite (ao vivo) para os polos de apoio presencial distribuídos em todo o território nacional. Durante a transmissão, o aluno pode sanar suas dúvidas e enviar comentários sobre a teleaula via chat, sincronicamente, por intermédio de um monitor que o acompanha no polo. Há um professor auxiliar no estúdio que recebe os questionamentos e/ou comentários no chat e envia ao professor temático, por meio do teleprompter, que irá responder, sempre se reportando ao aluno que fez a questão e também seu polo. Para complementar a semana de estudos, o aluno tem um conjunto de atividades teóricopráticas, disponibilizadas no Moodle, com uma carga horária de 16 horas e 40 minutos, planejadas pelo professor temático sobre os conteúdos do tema estudado, e inclui, por exemplo, leituras, vídeos, fórum, atividades, etc. Primeiramente, os discentes - duzentos e oitenta e dois matriculados - participaram do momento da aula-atividade, da temática A influência das pesquisas na formação do professor, respondendo ao piloto de apoio, com questões abertas e fechadas. Em seguida, selecionamos seis participantes para continuarem na pesquisa, que participaram de dois Fóruns: apresentação e relato introdutório e experiência no uso do AVA. Os 06 participantes são oriundos da escola pública, idade entre 25-48 anos, todos cursando a primeira graduação.

Para descrever e interpretar o fenômeno - as percepções que emergem dos alunos do curso de Pedagogia EaD sobre o planejamento, elaboração e utilização de materiais didáticos disponibilizados em ambiente virtual de aprendizagem - seguimos as rotinas de organização e interpretação propostas por Maximina Freire (2012). Iniciamos partindo da materialização textual das experiências vividas e contadas pelos alunos por meio das narrativas, tanto das questões dissertativas do piloto como dos fóruns de discussões, que os interpretamos, conjuntamente, na etapa chamada de textualização. Posteriormente, essas narrativas passaram pela etapa de tematização, caracterizada pelo "[...] momento de mergulho interpretativo que permite: identificar unidades de 
significado, refinar e ressignificar tais unidades [...], até que seja possível revelar os temas hermenêuticos-fenomenológicos e suas famílias" (FREIRE M., 2012, p. 195, grifo da autora). Foram inúmeras idas e vindas para emergirem os temas e seus desdobramentos, representados por "substantivos que capturam e explicitam os significados implícitos nos textos originais e, por seu sentido intransitivo, evidenciam o percurso entre a aparência e a essência, indicando os construtos que constituem o fenômeno - os temas hermenêutico-fenomenológicos -, revelando sua natureza e identidade" (FREIRE M., 2012, p. 192-193), correspondendo, assim, à reprodução do ciclo de validação. A título de esclarecimento, os TEMAS serão grafados em letra maiúscula, os subtemas em negrito e os subsubtemas em negrito/itálico.

\section{BUSCA}

O tema BUSCA configura-se como um ponto de partida, que impulsiona os participantes na realização de um curso de Pedagogia na modalidade a distância. Nessa perspectiva, constatamos que os participante optam pela escolha de um curso de Pedagogia EaD por razões diversas: a oportunidade, o tempo e o custo que terão disponíveis, como ilustra o excerto a seguir: "[...] considero a EAD uma excelente opção para casos assim como o meu... que já tenho meus 35 anos, compromissos com trabalho e casa, menos tempo" (Participante 2 - Fórum apresentação) e, também, o relato da Participante 4 Fórum apresentação: "essa é minha primeira faculdade, e decidi fazer a distância, pois tenho um filho e não queria me ausentar todos os dias à noite".

Interpretamos que a EaD continua sendo uma possibilidade de democratização do ensino superior com qualidade no Brasil, superando as barreiras geográficas e favorecendo o gerenciamento do tempo dos alunos. Compreendemos também que "[...] tal formação só será possível se a aprendizagem estiver fundamentada na experiência do contato direto com a vida cotidiana desse educando e em sintonia com sua futura carreira profissional" (AZEVEDO, 2007, p. 13). Evidenciamos nos relatos, também, os desafios quanto à tecnologia, conforme segue a narrativa: "[...] para que eu conseguisse entrar no ambiente virtual foi muito desgastante, [...] chegou um dia que me vi obrigada a fazer um curso básico de informática e aí foi melhorando" (Participante 3 Fórum apresentação).Entendemos que a instituição de ensino, ao definir os seus aspectos organizacionais do modelo pedagógico para EaD, deva considerar "[...] 0 universo sociocultural dos possíveis alunos, possibilitando a caracterização dos interesses e das necessidades deles" (CLEMENTINO, 2015, p. 155), lembrando que a tecnologia deve ser definida, assim como suas funcionalidades, para propiciar aos alunos o suporte necessário para sua utilização.

\section{FLUÊNCIA}


A interpretação do tema FLUÊNCIA mostrou-se pertinente para a nossa compreensão do fenômeno pesquisado, pois os participante apresentam suas vivências, evidenciando a necessidade de conhecer e utilizar de maneira correta o AVA, aspirando assim a construção do conhecimento. O que pode ser considerado na narrativa: "[...] sempre utilizei muito os recursos do Moodle para ter certeza do entendimento do material disponibilizado. [...] me sinto realizada fazendo a faculdade mesmo a distância, não me sinto menos dentro do assunto [...]" (Participante 4 - Fórum apresentação). Cabe observar, também, a importância de entender o uso dos recursos e atividades do ambiente virtual de aprendizagem, pois "[...] certamente, o aluno precisa ter equipamento e software necessários para acompanhar o curso EAD, usando de forma adequada a tecnologia" (BEHAR, 2009, p. 26). Por esse ângulo, compartilhamos o relato da Participante 3: "[...] chegou um dia que me vi obrigada a fazer um curso básico de informática e aí foi melhorando, o ambiente foi ficando mais acessível e hoje ainda tenho algumas dificuldades, mas tiro de letra; quando algo não dá certo, peço ajuda às colegas". Esta experiência nos desvela que, para os alunos se apropriarem dos recursos e atividades do AVA, eles procuram estratégias para sanar as dificuldades, realizando cursos ou mesmo esclarecendo dúvidas com os colegas de curso.

Constatamos a importância do tutorial disponibilizado pela instituição pesquisada, que auxilia na aprendizagem, orientando o aluno na utilização do AVA, o que se destaca no relato de um participante respondente do piloto de apoio, afirmando que o Moodle "[...] é direto e bem explicado, além de oferecer vídeos sobre toda a utilização". Ainda nesta perspectiva, dentre as facilidadesvivenciadas e relatadas pelos participantes, "você pode acessar as atividades e planos de ensino de qualquer lugar que tenha internet" (piloto de apoio). Percebemos que se evidencia "[...] a flexibilidade de tempo e espaço na EAD, os alunos precisam se empenhar em definir horários fixos de estudo em casa e/ou no trabalho para se dedicar ao curso e ter disciplina para tal" (BEHAR, 2009, p. 26). Para interpretar os desafios que envolvem a FLUÊNCIA, partimos do subsubtema dificuldades, que emergiu nas narrativas e aqui está materializado no excerto: "foram aulas fora do ar, impossibilidade de entrar no AVA, na sala de estágio etc. São problemas que na modalidade a distância ocorrem e que são muito ruins!" (Participante 2 - Fórum apresentação). Relacionamos, assim, as dificuldades de acesso às bandas de maior velocidade, que estão diretamente ligadas ao custo elevado ou à falta de disponibilidade do serviço na área em que moram. Entendemos que o acesso à internet de baixa velocidade traz dificuldades ao aluno, pois este não conseguirá utilizar todos os recursos e atividades disponíveis para realização do curso, como, por exemplo, assistir ou baixar uma teleaula, realizar uma atividade, fazer download de arquivos, etc. Esse é o caso da Participante 3 - Fórum apresentação ao narrar, sua experiência, que "[...] em algumas vezes as teleaulas não baixam e fica muito complicado para rever as teleaulas" 
- provavelmente sua internet é limitada.

\section{VIAS}

O tema VIAS permeia a vivência dos alunos e podemos refletir sobre a organização curricular da universidade investigada que é percebida pela Participante 2 (Fórum apresentação): "[...] gosto ainda da forma como são dados os Módulos, por temas e áreas integradas, dando uma noção do todo, não como era antigamente, pelas disciplinas fragmentadas". Salientamos, ainda, que a abordagem do currículo por eixos temáticos, integrando seus conteúdos, reduz a fragmentação dos saberes e das formas de ensinar e aprender. Nesse momento, exploramos a interpretação da abordagem do conteúdo, partindo das experiências relatadas pelos participantes, conforme relato no piloto de apoio: "os professores buscam aplicar atividades do cotidiano e atuais, assim se torna fácil de compreender e refletir sobre o tema". Percebemos que, para os alunos, os conteúdos abordados nos módulos são atualizados, fazem parte do seu cotidiano e são de qualidade. Nesse momento, retomamos Clementino (2015, p. 153), para nos esclarecer que "[...] os conteúdos necessitam de organização e integração de conceitos, conhecimentos e experiências em relação aos objetivos e interesses dos alunos. O que foi planejado só será válido se for algo útil para o aluno".

A diversidade de mídias para abordagem dos conteúdos emergiu positivamente nas narrativas, como, podemos constatar o trecho "gosto muito de como as aulas são planejadas, além das matérias do Guia de Estudo, temos a Leitura Ativa que é minha parte favorita, pois sempre colocam textos, vídeos, entrevistas que me auxiliam muito nas aulas" (Participante 1 - Fórum apresentação). Por esse ângulo, percebemos que, na instituição pesquisada, os alunos têm acesso ao conteúdo por diferentes mídias, o que fomenta o envolvimento do aluno com esses conteúdos. Outro ponto levantado pelos participantes foi o tempo destinado para a realização das leituras ou para assistir aos vídeos e usar outras mídias. Segundo a Participante 1 (Fórum experiência), o "[...] tempo estimado para o estudo, que vem denominado para cada atividade, nos facilita muito". Neste caso, entendemos que a abordagem do tempo precisa ser determinada no planejamento, prevendo assim a duração de cada apresentação de conteúdo, como também a proposição de atividade (FILATRO; CAIRO, 2015). Mas, em contrapartida, um relato exibe um aspecto negativo no que tange à abordagem de carga horária das atividades, conforme relato da Participante 4 - Fórum experiência, "[...] a grande realidade é que alguns professores dão tantas coisas pra fazermos que eu, pelo menos, não dou conta de fazer tudo naquela semana, mas em outros casos dá pra ir mais a fundo, acho que isso vai também do interesse do aluno pela matéria".

Há de se considerar, nesse momento, a "[...] duração de uma unidade de estudo - o 
tempo estimado para que as atividades sejam realizadas e concluídas. Esse é um exercício fantástico, que possibilita ao educador colocar-se no lugar do aluno e apurar sua proposta de interação" (FILATRO; CAIRO, 2015, p. 233). Não se tem um manual detalhado com o tempo de realização de cada atividade, contudo precisa-se levar em conta no planejamento e se concentrar em aumentar o tempo do que é considerado relevante e eliminar a sobrecarga. Nessa lógica, Filatro e Cairo (2015, p. 233) apontam alguns caminhos: simular a realização de parte de uma atividade proposta aos alunos ler algumas páginas de um livro, resolver um exercício, publicar uma mensagem no fórum - pode dar indicações preciosas sobre quanto tempo será consumido". Assim, compreendemos que a produção didática dirigida à $\mathrm{EaD}$ se torna desafiante para 0 docente ser autor do seu próprio discurso, ouvir outras vozes teóricas e ao mesmo tempo escolher com que voz quer dialogar com seus alunos. É imperativo lembrarmos que a "[...] autoria do professor não está restrita ao aspecto da técnica, ela precisa ser original na sua prática pedagógica, singular na forma que estabelece o seu diálogo pedagógico, deixando as marcas do seu processo de criação e de construção do conhecimento" (RICARDO, 2013, p. 73).

Os alunos declaram que são despertados ao aprofundamento dos temas pela necessidade de pesquisa, como, por exemplo, "[...] me direciona nos estudos e me desperta para novas possibilidades de aprendizagem (piloto de apoio)". Logo, compreendemos que a "[...] pesquisa é vista como fundamento docente e discente, não só para construir conhecimento, mas igualmente para pleitear formação melhor" (DEMO, 2009, p. 3). Esse subtema se desdobra na relação teoria e prática. Nessa interpretação, um trecho que nos chamou a atenção foi no piloto de apoio: "[...] normalmente aparecem situações na creche em que eu lembro de ter visto nas teleaulas", que nos faz refletir a necessidade de articular a formação inicial à formação em serviço, numa aprendizagem contínua, evidenciando assim a reflexão crítica sobre a prática (FREIRE P., 1996). Outro subtema que emergiu nas experiências vivenciadas pelos alunos com o AVA foi a convergência das temáticas dos módulos na realização dos projetos, de acordo com os fragmentos selecionados: "[...] os projetos são excelentes, claros, objetivos, com uma bagagem didática muito grande e rica de conhecimento [...]" (Participante 5 - Fórum experiência). Positivamente, a instituição pesquisada utiliza, como um dos instrumentos de avaliação, os projetos que permitem a reflexão crítica e a convergência dos conteúdos trabalhados pelos alunos, partindo do cotidiano do aluno e de sua realidade local. Ademais, entendemos que o processo de avaliação precisa estar "[...] o mais adequado aos objetivos da instituição e ao perfil do público-alvo, o processo avaliativo deve ser coerente com cada curso e cada objetivo" (CLEMENTINO, 2015, p. 188) e seguir as determinações oficiais propostas pelos órgãos do MEC. 


\section{MEDIAÇÃO}

A MEDIAÇÃO entre professor e aluno é um tema que impera nas experiências e vivências dos alunos nesta instituição de ensino, conforme seguem na narrativa: "os professores estão sempre dispostos na teleaula, acho que o que mais é importante são as perguntas que podemos fazer ao vivo para tirar dúvidas" (Participante 4 - Fórum experiência). Retomamos agora o contexto da universidade investigada, onde detalhamos o momento síncrono, por meio do chat, durante a teleaula transmitida ao vivo, como sendo uma possibilidade de os professores comentarem mensagens dos alunos ou sanarem suas dúvidas, fato que consideramos ser um diferencial para os discentes. "Assim, o papel das TICs é contribuir para 'diminuir' essa 'distância pedagógica', assegurando forma de comunicação e interação entre os 'atores' envolvidos no processo de construção de conhecimento pela EAD" (BEHAR, 2009, p. 23).

Nessa comunicação, emergem os saberes do professor, suas contribuições referentes aos conteúdos e as orientações necessárias, como se pode constatar no excerto: "[...] percebo a disposição dos professores tanto para ministrar as aulas, quanto para esclarecer possíveis questionamentos, prezando sempre por manter a clareza" (piloto de apoio). Compreendemos que todos esses momentos se tornam significativos para a aprendizagem, pois os alunos percebem a presença do professor, mesmo sendo num curso de modalidade a distância. Essa presença se evidencia com o fato de que o professor ministra sua aula, orienta as atividades propostas, etc. Por outro lado, nas narrativas emergiram observações quanto à falta de feedback nos fóruns propostos pelos docentes na aula-atividade, o que causou insegurança nos discentes em relação a saber se os objetivos propostos no fórum foram alcançados com êxito, pois não houve uma discussão após sua postagem, nem com a intervenção do professor, nem dos colegas de turma. O que percebe-se na narrativa: "[...] muitas vezes nos fóruns não sabemos se o que fizemos está certo ou não, acaba sendo uma atividade vazia sem propósito final, por não termos uma devolutiva" (Participante 6 - Fórum apresentação).

Observamos que a organização do aprender e ensinar se faz por meio dos conteúdos, envolvendo também a relação professor-aluno nos fóruns de discussões, que, no caso da instituição pesquisada, trata-se de um momento síncrono de muito valor didático, pois se o fórum precede ou sucede uma teleaula e o docente tem um período disponível para acompanhar, entendemos que sua participação se torna fundamental. Concerne, ainda, assim considerar que o professor precisa articular ao seu discurso didático, seus saberes práticos e teóricos, de maneira clara, objetiva, compreensível e dialógica com vistas à mediação pedagógica (RICARDO, 2013), provocando no aluno o comprometimento, superação, criticidade e aprendizado, substantivos que 
emergiram nos excertos dos participantes, ao relatarem suas experiências e vivências.

\section{Para (não) concluir}

A vivência do fenômeno pesquisado oportunizou para essas pesquisadoras a interpretação possível das narrativas dos alunos de um curso de Pedagogia EaD, que precisam ser consideradas no momento do planejamento, elaboração e organização dos conteúdos didáticos pelos professores que atuam na $\mathrm{EaD}$, pois a subjetividade dos atores (docentes e discentes) envolvidos na EaD deve ser contemplada. Nesse sentido, é pertinente relembrar as considerações do Conselho Nacional de Educação ao estabelecer as Diretrizes e Normas Nacionais sobre a EaD, que em seu artigo $2^{\circ}$ destaca, entre outros aspectos, a necessidade de articular "[...] a subjetividade e a participação democrática nos processos de ensino e aprendizagem em rede, envolvendo estudantes e profissionais da educação [...] que desenvolvem atividades educativas em lugares e/ou tempos diversos" (BRASIL, 2016, p. 1). Ademais, ao oportunizar que esses futuros professores narrassem suas vivências no AVA, compreendemos o sujeito no sentido e significado dado para as suas experiências, reconhecendo, por meio de suas narrativas, a essência da história vivida. Revelando, assim, uma interpretação possível para o fenômeno pesquisado, entendendo que outros pesquisadores e outras experiências vivenciadas podem propiciar novos olhares para a pesquisa.

\section{Referências}

AZEVEDO, Adriana Barroso de. Projetos Pedagógicos na EAD: da concepção à prática diferenciada. [2007]. Disponível em: $<$

http://www.academia.edu/499009/Projetos_pedag\%C3\%B3gicos_na_EAD_Da_concep $\% \mathrm{C} 3 \% \mathrm{~A} 7 \% \mathrm{C} 3 \% \mathrm{~A} 30$ \%C $3 \% \mathrm{A0}$ _pr\%C3\%A1tica_diferenciada>. Acesso em: 14 maio 2018.

BEHAR, Patricia Alejandra. Modelos Pedagógicos em educação a distância. In: BEHAR, Patricia Alejandra (Org.). Modelos pedagógicos em Educação a Distância. Porto Alegre: Artmed, 2009. p. 15-32.

BRASIL. Ministério da Educação. Conselho Nacional de Educação. Câmara de Educação Superior. Resolução CNE/CES n 1, de 11 de março de 2016. Estabelece Diretrizes e Normas Nacionais para a Oferta de Programas e Cursos de Educação Superior na Modalidade a Distância. Diário Oficial da União, Brasília, 14 mar. 2016. Seção 1, p. 23-24. Disponível em: . Acesso em: 14 maio 2018. 
CLANDININ, D. Jean; CONNELLY, F. Michael. Pesquisa narrativa: experiências e história na pesquisa qualitativa. Tradução de Grupo de Pesquisa narrativa e Educação de Professores ILEEL/UFU. 2. ed. Uberlândia: EDUFU, 2015.

CLEMENTINO, Adriana. Planejamento pedagógico para cursos EAD. In: KENSKY, Vani Moreira. Design instrucional para cursos on-line. São Paulo: Senac São Paulo, 2015. p. 151-190.

DEMO, Pedro. Educação hoje: "novas" tecnologias, pressões e oportunidades. São Paulo: Atlas, 2009.

FILATRO, Andrea; CAIRO, Sabrina. Produção de Conteúdos Educacionais. São Paulo: Saraiva, 2015.

FREIRE, Maximina Maria. Da aparência à essência: a abordagem Hermenêuticofenomenológica como orientação qualitativa de pesquisa. In: MELLO, Lucrécia Stringhetta; ROJAS, Jucimara (Org.). Educação, pesquisa e prática docente em diferentes contextos. Campo Grande/MS: LIFE Editora, 2012. p. 181-199.

FREIRE, Maximina Maria. Uma abordagem metodológica e uma teoria do conhecimento: relato de um encontro e a emergência de uma tessitura. In: FREIRE, Maximina Maria; BRAUER, Karin Claudia Nin (Org.). Vias para pesquisa: reflexões e mediações. São Paulo: Grupo de Pesquisa sobre a abordagem hermenêuticofenomenológica e complexidade (GPeAHFC/CNPq), 2015. E-book. p. 173-180.

FREIRE, Paulo. Pedagogia da autonomia: saberes necessários a prática educativa. São Paulo: Paz e Terra, 1996. (Leitura).

PALLOFF, Rena M.; PRATT, Keith. Construindo comunidades de aprendizagem no ciberespaço: estratégias eficientes para a sala de aula online. Tradução de Vinícius Figueira. Porto Alegre: Artmed, 2002.

PASSEGGI, Maria da Conceição. A experiência em formação. Educação, Porto Alegre, v. 34, n. 2, p. 147-154, maio/ago. 2011.

RICARDO, Eleonora Jorge. Educação a Distância: professores-autores em tempos de cibercultura. São Paulo: Atlas, 2013. 